\title{
Cooperation and the variation of payoff in non-zero-sum games'
}

JERRY G. ELLS AND VELLO SERMAT

UNIVERSITY OF OREGON

The relationship between cooperative play and specific matrix entry values was examined for three non-zero-sum games. A competitive choice in games II and III offered the possibility of equal differential gain over the other player, but differential gain greater than that offered by a competitive choice in game I. The amount of absolute gain available through a competitive choice was the same in games I and II, but greater in game III. Thus, competition offered the least amount of differential gain for game I, equal differential gain for games II and III, equal absolute gain for games I and II, and greatest absolute gain for game III. Ss were found to be highly cooperative in game I, somewhat less cooperative in game II, and markedly less cooperative in game III. The predominantly cooperative behavior of $S S$ in games I and II is at variance with findings previously reported in the literature.

Strategies adopted in two-person non-zero-sum games have been demonstrated to differ from those predicted by formal game theory (Scodel, Minas, Ratoosh, \& Lipetz, 1959). The purpose of the present study is to ascertain the contribution of specific relationships among matrix entry values to the discrepancy between theoretical and actual game behavior.

The general payoff matrix for two-person non-zerosum games is shown in the left upper corner of Fig. 1. Each player has two choices, RED or BLACK. In the present study, a RED choice is referred to as a competitive choice and a Black choice as cooperative. The four possible outcomes are denoted by a couple $\left(\mathrm{X}_{\mathbf{i}}, \mathrm{X}_{\mathbf{j}}\right)$. The first number of a couple is the value of the outcome to person 1 , and the second number, the value to person 2 .
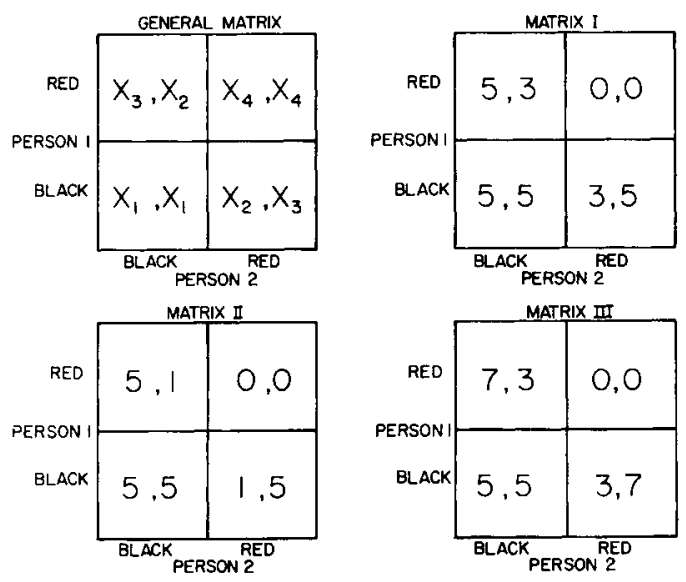

Fig. 1. The general form of the payoff matrix, and the three nonzero-sum payoff matrices used in the experiment.
A type of game, referred to as a "Chicken" game (Rapoport \& Chammah, 1965), is subject to the following restrictions:

(i) $\mathrm{x}_{4}<\mathrm{x}_{2}<\mathrm{x}_{1}<\mathrm{x}_{3}$

(ii) $2 \mathrm{X}_{1}>\mathrm{X}_{2}+\mathrm{X}_{3}>2 \mathrm{X}_{4}$

In "Chicken" games, outcomes $\left(\mathrm{X}_{2}, \mathrm{X}_{3}\right)$ and $\left(\mathrm{X}_{3}, \mathrm{X}_{2}\right)$ for players 1 and 2, respectively, are greater than outcome $\left(\mathrm{X}_{4}, \mathrm{X}_{4}\right)$. Matrix III meets these conditions, but condition (i) fails in the other two, in that $x_{4}<x_{2}<x_{1}=$ $\mathrm{X}_{3}$ (see Fig。1).

Minas et al (1960) report an unexpectedly high frequency of competitive choices when condition (i) fails. Since a player could not gain more points by choosing RED over BLACK when $\mathrm{X}_{4}<\mathrm{X}_{2}<\mathrm{X}_{1}=\mathrm{X}_{3}$, the interpretation was that the predominance of RED choices indicated an attempt to maximize differential gain rather than absolute gain.

Rapoport et al (1965) report that for Prisoner's dilemma matrices, as the difference, $\mathrm{X}_{3}-\mathrm{X}_{2}$, increases, the frequency of cooperative choices decreases. His data, however, do not indicate the relative contribution of each component, $\mathrm{x}_{3}$ and $\mathrm{x}_{2}$, in the relationship between the frequency of cooperative choices and $x_{3}-x_{2}$, since $x_{2}$ is always the negative of $x_{3}$, i.e., $x_{2}=-x_{3}$.

The present study employed three matrices, $I, I I$, and III, shown in Fig. 1. Matrix II differs from Matrix I only in that $\mathrm{X}_{2}$ is decreased; Matrix III differs from Matrix I only in that $X_{3}$ is increased. The difference $\mathrm{X}_{3}-\mathrm{X}_{2}$ is equal for Matrices II and III. Condition (i) fails for Matrices I and II, i.e., $\mathrm{x}_{4}<\mathrm{x}_{2}<\mathrm{X}_{1}=\mathrm{X}_{3}$.

The specific hypothesis under investigation is that both an increase in $\mathrm{X}_{3}$ and a decrease in $\mathrm{X}_{2}$ are associated with a decrease in cooperative choices; however, an increase in $\mathrm{X}_{3}$, which results in both absolute gain and differential advantage over the other player, should have more effect than does a decrease in $\mathrm{X}_{2}$ which only magnifies the differential advantage for the player, without increasing his absolute gain. Of secondary interest is whether the larger monetary payoff associated with $\mathrm{x}_{4}<\mathrm{x}_{2}<\mathrm{x}_{1}=\mathrm{x}_{3}$ will induce a higher degree of cooperative play than that reported by Minas et al (1960). Method

The Ss were 36 male students from introductory psychology courses at the University of Oregon. Four Ss separated by opaque screens participated simultaneously. In front of each $\mathrm{S}$ was a panel displaying one of the three payoff matrices. One red and one black pushbutton were located to the left of the matrix. The Ss were randomly assigned to Groups I, II, and III, which corresponded to the matrices shown in Fig. 1. Each $\mathrm{S}$ 
was told that he had been paired with one of the other three persons present, that his and the other person's choices would jointly determine his payoffs and that there would be 100 successive trials. After each trial, a lighted cell on the S's panel indicated the payoffs of both participants. The Ss were informed that they would be paid at the end of the experiment according to the following procedure. Each $S$ would toss a die once. The value of the upturned face multiplied by the point total and divided by ten determined the amount the $S$ received in cents. All the procedures were carried out in accordance with the explanation given to the Ss.

Results

Figure 2 shows the mean per cent of black (cooperative) choices over blocks of 20 trials for Groups I, II, and III. The 100-trial means were: Group I, 98; Group II, 78; and Group III, 47. The average point total was 489 for Group I, 391 for Group II, and 360 for Group III.

The difference in frequency of cooperative choices between groups is significant at the .005 level $(F=12.96$, $\mathrm{df}=2 / 33$ ). Tukey's procedure of multiple comparisons revealed significant differences over 100 trials between Groups I and III $(p<.01)$, and between Groups II and III

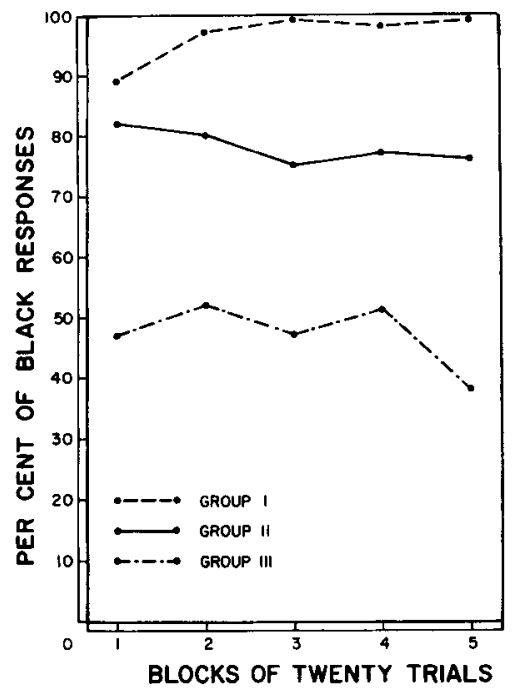

Fig. 2. Per cent of black (cooperative) responses. $(p<.01)$. The difference between Groups I and II was approaching significance at the .10 level.

\section{Discussion}

The results for the three games indicate that increasing $\mathrm{X}_{3}-\mathrm{X}_{2}$ is associated with a decrease in cooperative choices and that of the two components, $x_{3}, x_{2}$, increasing $\mathrm{X}_{3}$ reduces cooperation more than does decreesing $x_{2}$. It is concluded that $x_{3}-x_{2}$ per se is not the crucial variable affecting cooperative play since for both Groups II and III, $\mathrm{X}_{3}-\mathrm{X}_{2}=4$, and Groups II and III were shown to differ.

The interaction between the goals of maximizing total gain and differential gain for Group III is the most plausible explanation for the marked reduction in cooperation for Group III as compared with Groups I and II, since the groups in order of decreasing cooperation are I, II, and III.

Both games I and $\mathrm{II}_{\text {s }}$ for which $\mathrm{X}_{4}<\mathrm{X}_{2}<\mathrm{X}_{1}=\mathrm{X}_{3}$, were played in a predominantly cooperative manner. This suggests the main goal for these two games was that of maximizing absolute gain, rather than maximizing differential gain as was concluded in the Minas et al (1960) study where only 48 per cent of choices were cooperative. The only major procedural differences between the two studies are the number of trials, and maximum possible payoff. The game in the Minas et al (1960) study consisted of 30 trials, with a maximum possible gain of \$.90. All games in the present study were 100 trials in length and the maximum possible gain for games I and II was $\$ 3.00$. Thus, increasing the maximum possible payoff may increase the degree of cooperation.

\section{References}

Minas, J. S., Scodel, A., Marlowe, D., \& Rawson, H. Some descriptive aspects of two-person non-zero-sum games: II. Conflict Resol., 1960, 4, 193-197.

Rapoport, A., \& Chammah, A. N. Prisoner's dilemma, A study in conflict and cooperation. Ann Arbor: University of Michigan Press, 1965.

Scodel, A., Minas, J .S., Ratoosh, P., \& Lipetz, M. Some descriptive aspects of non-zero-sum games. Conflict Resol., 1959, 3, 115-119.

\section{Note}

1. This research was conducted by the senior author in partial fulfillment of the requirements for master's thesis at the University of Oregon and was supported by NSF Grant GS-583 to the second author. 